and gender disadvantages in access to food are perhaps the most likely explanation for the association of fatigue with low body mass index.

Mental health factors, notably the comorbidity with other physical problems, and symptoms of depression and anxiety, had the strongest associations with chronic fatigue. Common mental disorders and medically unexplained symptoms are among the most common causes of morbidity in developing countries. However, less than a third of clinically significant morbidity is detected, ${ }^{13}$ and fatigue may be a key problem in these disorders.

In conclusion, our main finding is that the strongest association of chronic fatigue in developing countries is with mental illness. Chronic fatigue is often comorbid with other medically unexplained physical symptoms, suggesting that such symptoms are part of a medically unexplained somatic syndrome. ${ }^{3}$ Practitioners in developing countries should investigate the psychological and social determinants of chronic fatigue before assuming that it is the result of anaemia or a nutritional deficiency. The growing evidence for effective treatments should provide the basis for guidelines for management of such symptoms. ${ }^{14}{ }^{15}$

We thank the Directorate of Health Services, Government of Goa, which has collaborated with the project from its inception. We also thank Suhas Lavanis, Chandrakant Mhambrey, and Arvind Salelkar for their support for the study; Sheela Gupte and Prasad Nevrekar for gynaecological supervision; Tamara Hurst and Fiona Marquet in London and Anil Pandey in India for their administrative support to the project. Finally, we acknowledge the contribution of the research team of the Stree Arogya Shodh Project.

Contributors: See bmj.com

Funding: This study was funded by a Wellcome Trust career development fellowship in clinical tropical medicine to VP.
Competing interests: None declared.

Ethical approval: The study received ethical approval from the ethics board of the London School of Hygiene and Tropical Medicine and the Independent Ethics Commission, Mumbai.

1 Bhatia JC, Cleland J. Self-reported symptoms of gynecological morbidity and their treatment in South India. Stud Fam Plann 1995;26:203-16.

2 Dineshkumar B, Raghuram TC, Radhaiah G, Krishnaswamy K. Profile of drug use in urban and rural India. Pharmacoeconomics 1995;7:332-46.

3 Wessely S, Nimnuan C, Sharpe M. Functional somatic syndromes: one or many? Lancet 1999;354:936-9.

4 Gender, reproductive health and weakness: experiences of slum dwelling women in Bombay, India, 1997. Rustenburg, South Africa: IUSSP Committee on Reproductive Health and University of Witswaterand, 1997.

5 Shiva M. Women and health. In: Mukhopadhyay A, ed. State of India's health. 1st ed. New Delhi: Voluntary Health Association of India, 1992:265-302.

6 Patel V, Rodrigues M, De Souza N. Gender, poverty and post-natal depression: a cohort study from Goa, India. Am J Psychiatry 2002;159:43-7.

International Institute for Population Sciences. National Family Health Survey-2, 1998-99:India. Mumbai: IIPS, 2001.

8 Patel V, Pereira J, Coutinho L, Fernandes R, Fernandes J, Mann A. Poverty, psychological disorder and disability in primary care attenders in Goa, India. Br J Psychiatry 1998:171:533-6.

9 Chaturvedi S, Sarmukaddam S. Somatizers in psychiatric care. Indian J Psychiatry 1987;29:337-42.

10 Patel V, Pereira J, Mann A. Somatic and psychological models of common mental disorders in India. Psychol Med 1998;28:135-43.

11 Skapinakis P, Lewis G, Meltzer H. Clarifying the relationship between unexplained chronic fatigue and psychiatric morbidity: results from a community survey in Great Britain. Int Rev Psychiatry 2003;15:57-64.

12 Astbury J. Gender disparities in mental health. In: World Health Organization. Mental health: a call for action by world health ministers. Geneva: ZHO, 2001:73-92

13 Ustun TB, Von Korff M. Primary mental health services: access and provision of care. In: Ustun TB, Sartorius N, eds. Mental illness in general health care: an international study. Chichester: John Wiley \& Sons, 1995:347-60.

14 Patel V, Araya R, Bolton P. Treating depression in developing countries. Trop Med Int Health 2004;9:539-41.

15 Sumathipala A, Hewege S, Hanwella R, Mann H. Randomized controlled trial of cognitive behaviour therapy for repeated consultations for medically unexplained complaints: a feasibility study in Sri Lanka. Psychol Med 2000;30:747-57.

(Accepted 22 March 2005)

doi 10.1136/bmj.38442.636181.E0

\section{A little give and take}

Mount Isa, a dusty mining town in the Australian outback, was not known for its pioneering medical practices, or so I thought. I worked there for six months in the hospital accident and emergency department with a team almost exclusively made up of ex-pat British doctors. The pace was gentle, and, although this was a working holiday for me, the emphasis was on the latter. The permanent staff were grudgingly resigned to the situation.

Members of the mining workforce would occasionally attend for the treatment of chemical burns to the eye. The patient would first have local anaesthetic applied to the cornea, then a device resembling a contact lens attached to a fine tube would be gently inserted under the eyelids and continuous irrigation applied with saline from a litre bag. A patient with kit in situ was a slightly disturbing sight, but the device's simplicity and effectiveness were impressive.

On moving to an accident and emergency department in the sprawling city of Brisbane, I was quick to call for the "contact lens irrigator" when faced with my first chemical burn to the eye. The nurse in charge simply gave me a bewildered look. She explained that eye irrigation was done by setting up a drip attached to a saline bag and standing over the supine patient while dripping the fluid into the eye. This was time consuming, ineffective, and not well tolerated, but was all that the staff knew.
A few telephone calls and several days later, an irrigator device arrived from Mount Isa. It was an instant hit, freeing up valuable time and stopping the nurses' shoes getting soaked. As far as I know, it is still in use to this day.

I sometimes feel that a junior doctor's existence is rather parasitic in nature-frequent moves from place to place (sometimes country to country) assimilating as much valuable experience as possible but giving little back to the local staff. On this occasion, however, I felt that I had passed on a little of what I had learnt on my travels as part payment for what I had received.

Luke Wheeler senior house officer, Medicine, University

Hospital of Wales, Cardiff (ldwheeler2000@yahoo.com)

We welcome articles up to 600 words on topics such as A memorable patient, A paper that changed my practice, My most unfortunate mistake, or any other piece conveying instruction, pathos, or humour. Please submit the article on http://submit.bmj.com Permission is needed from the patient or a relative if an identifiable patient is referred to. We also welcome contributions for "Endpieces," consisting of quotations of up to 80 words (but most are considerably shorter) from any source, ancient or modern, which have appealed to the reader. 